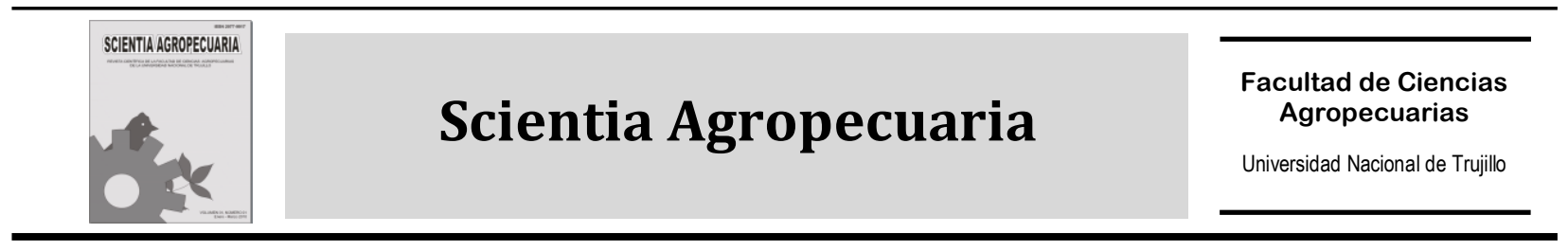

\title{
Predicción por redes neuronales artificiales de la calidad fisicoquímica de vinagre de melaza de caña por efecto de tiempo- temperatura de alimentación a evaporador-destilador flash Prediction by artificial neural networks of the physicochemical
quality of cane molasses vinegar by time-temperature effect of food
to flash evaporator-distiller
}

\author{
Víctor Vásquez V. ${ }^{1,}$, Carlos Lescano A. ${ }^{2}$ \\ ${ }^{1}$ Departamento de Ciencias Agroindustriales (Universidad Nacional de Trujillo) Avda. Juan Pablo II s/n Trujillo, Perú. \\ ${ }^{2}$ Facultad de Ciencias Agrarias, Universidad Privada Antenor Orrego, Av. América Sur 3145, Trujillo, Perú.
}

Recibido 29 enero 2010; aceptado 26 Marzo 2010

\begin{abstract}
Resumen
Se predijo por Redes Neuronales Artificiales (RNA) importantes características fisicoquímicas de vinagre de melaza: $\mathrm{pH}$, densidad, acidez total, etanol, aldehídos totales y furfural; obtenidas mediante operaciones de evaporación flash y clarificación por destilación flash. Melaza fermentada por vía alcohólica y acética, fue alimentada a un evaporador flash a cuatro temperaturas $\left(61,66,71\right.$ y $\left.76{ }^{\circ} \mathrm{C}\right)$ y tres tiempos $(25,35$ y $45 \mathrm{~min})$. La predicción se realizó con dos redes: RNA-A y RNA-B, ambas con buen desempeño. La RNA-A fue del tipo feedforward (FF), con algoritmos de entrenamiento Backpropagation (BP) y ajuste de pesos Levenberg-Marquardt (LM), topología: 6 entradas (datos de las operaciones de evaporación-destilación flash), 7 salidas lineales (características fisicoquímicas), 9 neuronas tangente sigmoidales en 1 capa oculta, coeficiente de momento 0.5 , tasa de aprendizaje 0.01 , meta del error 0.0001 y 20 etapas de entrenamiento. La RNA-A mostró mejor desempeño que un modelo estadístico de primer orden. La RNA-B igualmente FF, con algoritmos BP y LM, topología: 2 entradas (datos de la evaporación flash), 7 salidas lineales (características fisicoquímicas), 84 neuronas logaritmo sigmoidales en 1 capa oculta, coeficiente de momento 0.5, tasa de aprendizaje 0.01, meta del error 0.0001 y 300 etapas de entrenamiento. La RNA-B mostró igual capacidad predictiva que un modelo estadístico de primer orden con interacción de términos.
\end{abstract}

Palabras clave: Redes Neuronales Artificiales (RNA), vinagre de melaza, evaporador flash, destilador flash

\begin{abstract}
It was predicted via Artificial Neural Networks (ANN) important physicochemical characteristics of molasses vinegar: $\mathrm{pH}$, density, total acidity, ethanol, total aldehydes and furfural, obtained by flash evaporation operations and flash distillation clarification. Alcoholic and acetic fermented molasses were fed to a flash evaporator at four temperatures $\left(61,66,71\right.$ and $76^{\circ} \mathrm{C}$ ) and in three times (25, 35 and $\left.45 \mathrm{~min}\right)$. The prediction was made with two networks: ANN and ANN-A-B, both with good performance. The ANN-A was of the feedforward (FF) type with Backpropagation (BP) training algorithms and set of Levenberg-Marquardt (LM) weights adjustment, topology: 6 inputs (operations data of flash evaporation-distillation), 7 linear outputs (physicochemical characteristics), 9 tangent sigmoidal neurons in 1 hidden layer, 0.5 moment coefficient, 0.01 learning rate, 0.0001 error goal and 20 training stages. The ANN-A showed better performance than a statistical model of first order. The ANN-B also FF, BP and LM algorithms, topology: 2 inputs (data from flash evaporation), 7 linear outputs (physical and chemical characteristics), 84 logarithm sigmoid neurons in 1 hidden layer, 0.5 moment coefficient, 0.01 learning rate, 0.0001 error goal and 300 training stages. The ANN-B showed the same predictive capacity as a statistical model of the first-order with interaction of terms.
\end{abstract}

Keywords: Artificial Neural Networks (ANN), molasses vinegar, flash evaporator, flash distiller

\footnotetext{
* Autor para correspondencia.

E-mail: vjvv@hotmail.com (V. Vásquez)
} 


\section{Introducción}

El vinagre ha sido conocido por la mayoría de civilizaciones, como sazonador, preservante, o diluido como bebida. En la actualidad ha adquirido importancia en ensaladas, aderezos, salsas y es definido como un líquido con una cantidad específica de ácido acético apto para el consumo humano, resultante de la doble fermentación alcohólica y acética de productos de origen agrario que contengan azúcares o sustancias amiláceas (Joint FAO/WHO Food Standards Programme, 1987). El origen del producto no es tan sólo vinícola, existen vinagres que provienen de sidra, cereales, malta, miel o suero de leche. El Instituto del Vinagre (The Vinegar Institute USA, 2003), reporta que se ha producido por fermentación acética de una gran variedad de productos, incluyendo las melazas, debiendo llevar una leyenda que especifique su origen. Regulaciones en Estados Unidos, exigen que el vinagre debe contener por lo menos $4 \%$ de ácido acético.

La Región la Libertad, al noroeste del Perú, destaca por ser el primer productor de caña de azúcar (45.6\%), siendo su importancia económica variada ya que además de azúcar, el bagazo y la melaza constituyen importantes subproductos, que pueden contribuir al aumento del valor agregado de la industria azucarera (MINAG, 2009). La producción de vinagre, tiene como punto de partida al alcohol, el que puede ser obtenido por fermentación anaeróbica de azúcares mediante levaduras, las cuales no sólo forman alcohol etílico y gas carbónico, también compuestos congenéricos: alcoholes como el glicerol, 2feniletanol, los alcoholes pesados (aceite fusel), carbonilos (aldehídos y cetonas), ácidos orgánicos y esteres (García y López-Mungia, 1993; Suárez, 2002). El aceite fusel es una fracción con puntos de ebullición de 90 a $150^{\circ} \mathrm{C}$, y los aldehídos formados en la fermentación poseen puntos de ebullición entre 20.2 a $161.7^{\circ} \mathrm{C}$; el butiraldehído posee una temperatura de ebullición de $75.7^{\circ} \mathrm{C}$ (Brabec, 1981) y los esteres entre 32 y $213^{\circ} \mathrm{C}$
(Fasset, 1983). Achaerandio et al. (2002-a, b), reportan estudios de clarificación de vinagre blanco y rosé mediante decoloración por adsorción con resinas de intercambio iónico, con una eficiencia de 69 y $72 \%$ respectivamente. Asimismo decoloración de vinagre con carbón activado modificado con una eficiencia de $85.9 \pm 2.2 \%$. López et al. (2003) investigaron la capacidad de decoloración con carbón activado granular modificado de cáscara de coco con aire a $350^{\circ} \mathrm{C}$, obteniendo una capacidad de decoloración de 94 y $98 \%$ para los vinagres rojo y blanco, respectivamente.

Se han realizado investigaciones para aumentar la recuperación de ácido acético de procesos fermentativos, con varios solventes. Ince y Kirbaslar (2002) evaluaron la acción del butilacetato en la extracción de ácido acético a partir de soluciones diluidas, con un factor de separación (S) de 17.89. Reportan un $\mathrm{S}$ de un sistema agua-ácido acético-metil isopropil cetona de 18.031 .

El ácido acético posee punto de fusión y de ebullición de $118.1{ }^{\circ} \mathrm{C}$, pudiendo obtenerse conjuntamente con otros componentes de menor punto de ebullición mediante destilación flash. Esta técnica se ha reportado en la separación componentes en procesos de petroquímica, así como en sistemas de multietapas, en plantas comerciales de desalinización de agua de mar (Al-Shayji et al., 2005).

Los evaporadores flash son usados para concentrar líquidos con un alto contenido de sólidos, alta viscosidad, o con una alta tendencia a formar precipitados $\mathrm{e}$ incrustaciones; son usados para la eliminación de arsénico en agua para consumo humano de pozos profundos (Spinnler et al., 2000). Ovejero y Lesino (2003), definen al evaporador flash como aquel que produce una evaporación súbita, debido a que líquido caliente, entran al recinto a una menor presión y se esparce como una lluvia de gotas vaporizándose. Ovejero et al. (2000) 
mencionan que el evaporador flash permite un pequeño salto térmico, bajas pérdidas de presión, entrada simple y múltiples salidas, alta eficiencia, volumen pequeño, bajos costos de fabricación, baja susceptibilidad a la corrosión y a la suciedad.

El modelamiento matemático de un evaporador implica la realización de balances másicos, entálpicos y ecuaciones de velocidad de transferencia de calor a través del área de intercambio, que implica cálculos iterativos, lo cual puede alejar de obtener predicciones apropiadas. Más aún en el presente caso que la composición del vinagre de melaza es de naturaleza multicomponente, debido a congenéricos con distinto punto de ebullición, formados durante los procesos fermentativos. Un análisis de los fenómenos de transporte que se producen durante el proceso de evaporación, conduce al establecimiento de un modelo matemático estructural del proceso bastante complejo (Pérez-Akasuso et al., 2004). En la destilación flash, los modelos se han planteado como isotérmicos y adiabáticos con una sola fase líquido-vapor. Para mezclas multicomponentes el comportamiento es fuertemente no-ideal y con un gran número de componentes, que involucra un procedimiento iterativo bastante tedioso (Scenna, 1999).

Según Olmedo et al. (2006), se pueden plantear soluciones complementarias en la predicción utilizando de Redes Neuronales en sistemas de dimensión elevada. Las Redes Neuronales Artificiales (RNA) han despertado gran interés como modelo predictivo, son técnicas computacionales y representan un modelo matemático basado en el concepto de estructura neuronal de organismos inteligentes y que adquieren conocimiento a través de la experiencia (Mendes, 1999). Son muy útiles cuando no se dispone de informaciones matemáticas exactas, y puede ser capaz de resolver previsiones de problemas lineales y no lineales (Cruz et al., 1999). Se ha estudiado la aplicación de RNA en la predicción de desalinización de agua de mar utilizando destilación flash en sistemas de multietapas, en conjunción con técnicas estadísticas (AlShayji et al., 2005). Asimismo las RNA han demostrado ser herramientas de predicción en la caracterización de vinagres blancos de diferentes procedencias, apoyados con técnicas de HPLC, espectrofotometría de adsorción atómica, cromatografía de gases y análisis sensorial (Gerbi et al., 1998). Liu et al. (2008) reportan haber determinado contenido de azúcar de vinagre blanco usando espectroscopia infrarroja (visible y no visible) y RNA Backpropagation (BP). Generalmente se acepta que el rendimiento de una RNA multicapas adecuadamente diseñada, sea comparada, con una técnica clásica estadística. Una combinación de ambos métodos en forma híbrida podría ser altamente ventajosa. El modelamiento por RNA es esencialmente, una caja negra, no prioriza conocimiento acerca del proceso e ignora la existencia de algún conocimiento prioritario. La capacidad de la red para aprender aproximaciones no paramétricas o estructuras libres es válida, pero es frágil. Las RNA típicas tienen muchos parámetros internos (pesos y bias/sesgos) (Demuth y Beale, 2005) y estos podrían llevar a un sobrentrenamiento del ruido y a una función inadecuada, resultando una generalización pobre (Hussain et al., 2002).

La presente investigación, tiene como antecedentes que las técnicas de decoloración de vinagres tintos no poseen una coloración oscura difícil de remover, como es el caso de la melaza de caña, que el empleo del carbón activado implica procesos de modificación y regeneración a altas temperaturas con costos elevados y la adición de componentes para la extracción líquido-líquido de ácido acético puede incorporar sustancias de consumo restringido. En este sentido considerando el color oscuro del vinagre de melaza y que el ácido acético presente en este, posee una temperatura de ebullición cercana a $118^{\circ} \mathrm{C}$; es viable extraerlo clarificado a una alta presión, mediante destilación súbita o flash. La eliminación de aldehídos, antes de una operación de destilación a alta presión 
(evaporación flash), es importante para mejorar su calidad. En este sentido se emplearon los métodos de evaporacióndestilación flash. Las RNA se usaron como herramienta predictiva, evaluándose el efecto de cuatro temperaturas $\left(61,66,71\right.$ y $\left.76{ }^{\circ} \mathrm{C}\right) \mathrm{y}$ tres tiempos $(25,35$ y 45 minutos $)$ de alimentación a un evaporador-destilador flash, en características fisicoquímicas importantes de vinagre de melaza de caña de azúcar; comparándose la calidad del vinagre obtenido con la Norma Técnica Peruana para Vinagre (NTP.209.020).

\section{Materiales y métodos}

Se utilizó vinagre de melaza obtenido con Acetobacter sp., previamente fermentado con Saccharomyces cerevisiae CECT-350. Los medios de cultivo: agar Sabouraud y agar LEE, se utilizaron para la manutención de $S$. cerevisiae y Acetobacter sp, respectivamente.

$\mathrm{Se}$ utilizaron los reactivos: $\mathrm{K}_{2} \mathrm{~S}_{2} \mathrm{O}_{5}$, $\mathrm{Na}_{2} \mathrm{HPO}_{4} .12 \mathrm{H}_{2} \mathrm{O}, \mathrm{NaOH}, \mathrm{Na}_{2} \mathrm{H}_{2} \mathrm{EDTA}, \mathrm{HCl}$, $\mathrm{Na}_{2} \mathrm{~B}_{4} \mathrm{O}_{7} \cdot 10 \mathrm{H}_{2} \mathrm{O},\left(\mathrm{C}_{6} \mathrm{H}_{10} \mathrm{O}_{5}\right)_{\mathrm{n}}, \mathrm{C}_{5} \mathrm{H}_{4} \mathrm{O}_{2}, \mathrm{NaCl}$, $\mathrm{I}_{2}$; para determinación de aldehídos totales y furfural. El equipo experimental se muestra en la Figura 1, constituido por el evaporador flash y destilador flash.

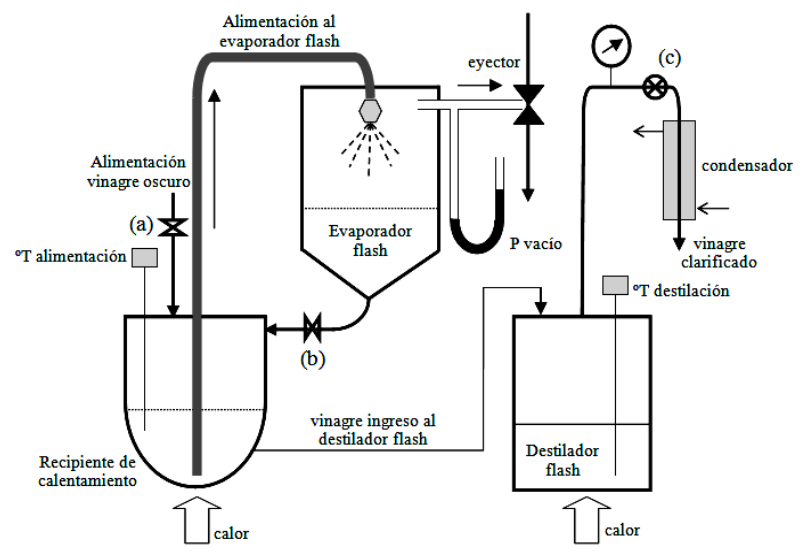

Figura 1. Diagrama de los componentes e interconexión del sistema evaporador - destilador flash

El evaporador flash tuvo como complemento un recipiente de calentamiento con temperatura controlada, con una entrada lateral para el retorno del vinagre del evaporador y tres conexiones de ingreso (tubo de alimentación - succión, sensor de temperatura y tubo aislado de succión de vinagre caliente).

El evaporador flash contó con dos conexiones (tubo de succión de vinagre caliente conectado a un aspersor y tubo de succión conectado al medidor de presión de vacío y al eyector); asimismo una tubería con llave de paso (b) al recipiente de calentamiento. La alimentación de vinagre se realizó introduciendo $1 \mathrm{~L}$ por el tubo de alimentación-succión con la llave (a) abierta, al concluir se cerró la llave (a), se verificó la temperatura alcanzada en el recipiente de calentamiento mediante el sensor de temperatura; al llegar a la temperatura, se puso en accionamiento el eyector mediante el suministro de agua por una bomba, la cual fue controlada con una llave de regulación con el objeto obtener la presión de vacío (manómetro de mercurio). Estabilizada la presión, se cerró la llave "b" e inmediatamente se abrió la llave "a" produciéndose la aspiración del vinagre de melaza por la tubería de succión e inmediata aspersión. Los vapores producidos en el evaporador fueron succionados por la corriente de vacío generada por el eyector. Terminada la aspiración se tomó el tiempo, se cerró la llave de control de flujo del eyector y detuvo el accionamiento de la bomba; luego se retornó el vinagre del evaporador flash al recipiente de calentamiento abriendo la llave "b", quedando listo el vinagre para reiniciar el calentamiento a la temperatura requerida $\mathrm{y}$ proceder a un nuevo proceso de succión y evaporación flash. El destilador flash contó con un recipiente de calentamiento a alta presión con termómetro, con una tubería de salida de vapores conectada al condensador, manómetro y válvula electromecánica "c". Para obtener el destilado se activo la fuente de calor, manteniendo la válvula "c" completamente abierta hasta la aparición de los primeros vapores por espacio de 30 segundos, momento en el cual se cerró la llave 
"c" hasta llegar a una presión de 1.1 bar y 120 ${ }^{\circ} \mathrm{C}$. La temperatura y presión se mantuvieron en estos rangos a través de la apertura y cierre de la válvula "c".

La investigación tuvo dos fases, en la primera se desarrolló la fase experimental y en la segunda se determinó la capacidad predictiva de las RNAs. Para el entrenamiento y validación de las RNA se utilizó una PC Pentium IV con software MATLAB 2009 (http://alvareitor.rogramasfull.com/descargarmatlab-2009-crack-gratis.html).

Durante la fase experimental al vinagre oscuro de melaza se le determinó previamente su volumen, pH, acidez total (ácido acético), aldehídos totales (acetaldehído), respectivamente. Seguidamente se le alimentó a un evaporador flash a temperaturas de 61 , 66,71 y $76{ }^{\circ} \mathrm{C}$, combinándolos con tiempos de 25,35 y 45 minutos (12 tratamientos y tres repeticiones). Al producto obtenido se le determinó su pH y volumen y se destiló en un sistema flash a una presión de 1.1 bar (120 ${ }^{\circ} \mathrm{C}$ ), obteniéndose vinagre clarificado, al que posteriormente a la determinación de su volumen y densidad, se le analizó el pH, acidez total, contenido de alcohol, aldehídos totales y furfural.

En la segunda fase se determinó la capacidad predictiva de dos Redes Neuronales A y B (Figuras 2 y 3), utilizándose aleatoriamente el $75 \%$ del conjunto de datos de entrada y salida para el entrenamiento de las respectivas Redes Neuronales, de acuerdo a los criterios de Lamrini et al. (2005) e Isasi y Galván (2004) para evitar el sesgo de información. El $25 \%$ de los datos restantes ( 9 tratamientos) fueron tomados como datos de validación de la capacidad predictiva de las Redes Neuronales. Para la determinación de la capacidad predictiva, se inició el entrenamiento con una topología básica (1 capa oculta y funciones de transferencia: tangente sigmoidal hiperbólica tansig - con salida lineal - purelin), aumentándose las neuronas en la capa oculta y evaluando el error cuadrático medio (mse), escogiéndose la topología con mínimo mse. Se continuo con un aumento de las etapas de entrenamiento evaluando la disminución del mse, evaluándose el impacto en el mse de modificaciones combinadas de las funciones de transferencia: tansig, purelin y logaritmo sigmoidal hiperbólica -logsig-; finalmente se evaluó la influencia en mse de la variación de la tasa de aprendizaje $(\alpha)$ y coeficiente de momento, obteniéndose la mejor topología.

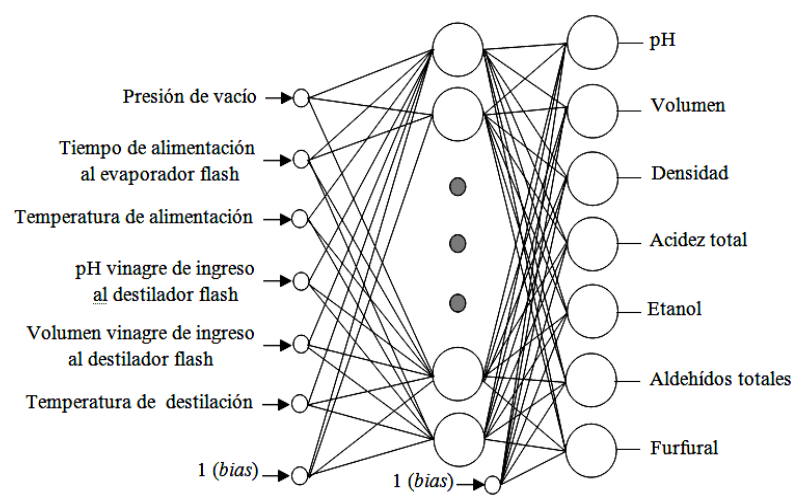

Figura 2. Topología de la Red Neuronal A

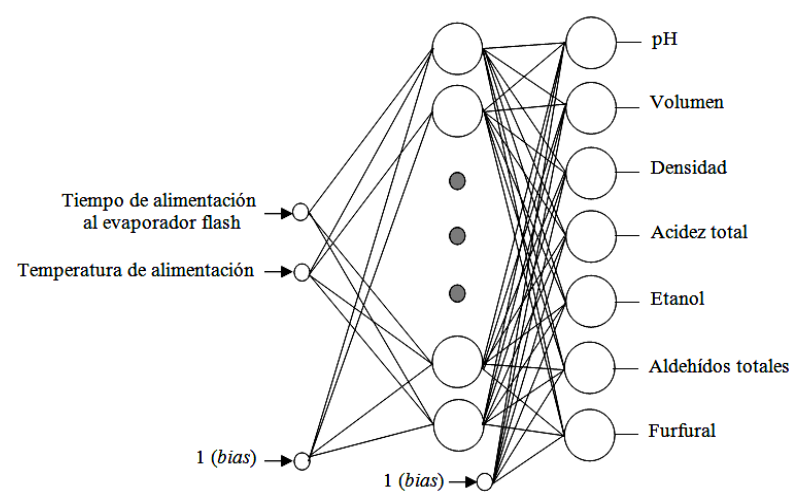

Figura 3. Topología de la Red Neuronal B

La predicción de las RNAs, fue evaluada con modelos estadísticos de regresión de primer orden, con interacción de términos y de segundo orden (Nalbant et al., 2007), seleccionando el modelo de regresión que produjo el menor el error porcentual promedio, entre las salidas obtenidas y las salidas esperadas.

Se realizaron análisis fisicoquímicos de: densidad a $20{ }^{\circ} \mathrm{C}$, contenido total de alcohol 
(Matissek et al., 1998), pH (Ott, 1987), acidez total (Pietrzyk y Frank, 1983), aldehídos totales y furfural (INDECOPI, 2003a,b).

\section{Resultados y discusión}

\subsection{Fase experimental}

La calidad fisicoquímica del vinagre oscuro de oscuro de melaza obtenido a través de los procesos de fermentación alcohólica y acética, utilizado para la fase experimental, es mostrada en la Tabla 1.

La NTP-209.020, no indica valores para vinagres provenientes de melaza de caña de azúcar, ni valores de aldehídos totales para vino y alcohol (INDECOPI, 1970). El valor de $5.85 \%$ de alcohol residual en vinagre de melaza (Tabla 1) es mayor que para los vinagres de vino y alcohol. Esto se debe a que durante la fermentación alcohólica se obtuvo hasta $10.5 \%$ de alcohol, lo que provocó una inhibición del Acetobacter sp. en la fermentación acética (Tesfaye et al., 2002).

$\mathrm{Se}$ determinaron diferencias estadísticas significativas $(\mathrm{p}<0.05)$ en las características de calidad fisicoquímica de vinagre clarificado de melaza: $\mathrm{pH}$, densidad, acidez total, contenidos de aldehídos totales y furfural; por efecto de cuatro temperaturas $\left(61,66,71\right.$ y $\left.76^{\circ} \mathrm{C}\right)$ y tres tiempos de alimentación (25, 35 y $45 \mathrm{~min}$ ) al evaporador flash. El vinagre clarificado, alimentado previamente en el evaporador flash a $76{ }^{\circ} \mathrm{C}$ y $45 \mathrm{~min}$ (Tabla 1 ), tuvo los valores menores de aldehídos totales y contenido de furfural.

El Ministerio de Salud de la República de Chile fija valores de toxicidad de sustancias peligrosas (Reglamento Sanitario de Manejo de Residuos Peligrosos, 2006), dentro de los cuales el acetaldehído y el furfural son considerados sustancias crónicas cancerígenas con una dosis letal de 661 y $50 \mathrm{mg} / \mathrm{kg}$, respectivamente. Los valores obtenidos para vinagre clarificado de melaza (aprox. 17.7 $\mathrm{mg} / \mathrm{kg}$ para el acetaldehído y $22.5 \mathrm{mg} / \mathrm{kg}$ para el furfural) están lejos de los reportados.

La FAO (2001) indica medidas a adoptarse como consecuencia de los cambios en el estado de aprobación de la Ingestión Diaria Admisible (IDA). Para el caso del furfural fija un IDA de 0 a $0.5 \mathrm{mg} / \mathrm{kg}$. Significa que para llegar a ese valor se tendría que consumir aproximadamente $28 \mathrm{~mL}$ de vinagre clarificado de melaza por persona por día.

Por otro lado de acuerdo a la NTP-211.001 para Pisco Peruano (INDECOPI, 2002), se reporta un valor máximo de acetaldehído de $60 \mathrm{mg} / 100 \mathrm{~mL}$ y furfural de $5 \mathrm{mg} / 100 \mathrm{~mL}$. Asimismo Tesfaye et al. (2002) reportan que el 5-hidroximetilfurfural es un componente común en vinagres balsámicos y está presente en concentraciones sobre $5500 \mathrm{mg} / \mathrm{kg}$. El vinagre clarificado de melaza tiene valores menores que los permitidos para el pisco y para los vinagres balsámicos.

Tabla 1

Características fisicoquímicas de vinagre oscuro de melaza y clarificado

\begin{tabular}{lcccc}
\hline \multicolumn{1}{c}{ Características } & $\begin{array}{c}\text { Vinagre } \\
\text { melaza }\end{array}$ & $\begin{array}{c}\text { Vinagre } \\
\text { clarificado }\end{array}$ & $\begin{array}{c}\text { NTP } \\
\text { vino }\end{array}$ & $\begin{array}{c}\text { NTP } \\
\text { alcohol }\end{array}$ \\
\hline pH potenciométrico & 3.35 & $2.57 \pm 0.01$ & 2.8 & 2.8 \\
Acidez total $(\mathrm{g}$ ácido acético/100 $\mathrm{mL})$ & 4.41 & $3.68 \pm 0.02$ & 4.0 & 4.0 \\
Aldehídos totales $(\mathrm{mg}$ acetaldehído/100 $\mathrm{mL})$ & 1.99 & $1.60 \pm 0.23$ & - & - \\
Densidad $20^{\circ} \mathrm{C}(\mathrm{g} / \mathrm{mL})$ & 1.01656 & $0.998 \pm 0.0007$ & $1.010-$ & $1.005-1.013$ \\
Alcohol total $(\%)$ & 5.85 & $0.92 \pm 0.09$ & 1.023 & - \\
Furfural $(\mathrm{mg} / 100 \mathrm{~mL})$ & n.d & $2.23 \pm 0.02$ & 1.0 & excento \\
\hline
\end{tabular}

n.d: no determinado

(i) Por destilación flash y previamente evaporado a $76^{\circ} \mathrm{C}$ y 45 minutos 
Del análisis estadístico se ha determinado que, para la eliminación de aldehídos totales y furfural, es determinante el aumento del tiempo y la temperatura de evaporación flash, habiéndose experimentado hasta $76^{\circ} \mathrm{C}$ por 45 minutos. Queda abierta la posibilidad de aumentar estos valores. El evaporador flash, operando a una presión de vacío entre 30.06$30.98 \mathrm{~mm}$ de $\mathrm{Hg}$, temperatura de alimentación de $76^{\circ} \mathrm{C}$ por un tiempo de 45 minutos, produce una evaporación súbita, pero todo el vapor no puede ser eliminado debido a que se condensa de manera inmediata en las paredes del evaporador. Un aislamiento de las paredes del evaporador ayudaría a mejorar la eficiencia (Ovejero et al., 2000).

\subsection{Evaluación de la capacidad predictiva de las redes neuronales y su validación}

La mejor topología seleccionada para el modelo neuronal de la secuencia-A fue: 6 entradas (una por cada variable), 7 salidas purelin, 9 neuronas tipo sigmoide tansig, 1 capa oculta, coeficiente de momento 0.5 , tasa de aprendizaje 0.01 , meta del error $0.0001 \mathrm{y}$ 20 etapas de entrenamiento. Se uso del algoritmo de entrenamiento BP y el algoritmo de ajuste de peso LM. En la Figura 4a se muestra el desempeño del aprendizaje del modelo neuronal, el cual no llegó a la meta de 0.0001 , pero produjo un error cuadrático medio mínimo de 0.00363408 .

Para el modelo neuronal de la secuencia-B la mejor topología fue: 2 entradas (una por variable), 7 salidas purelin, 84 neuronas tipo sigmoide logsig en 1 capa oculta, coeficiente de momento 0.5, tasa de aprendizaje 0.01, meta del error 0.0001 y 300 etapas de entrenamiento. Usándose análogamente los algoritmos de entrenamiento BP y de ajuste de peso LM. En la Figura $4 b$ se muestra el desempeño del aprendizaje, el cual tampoco llegó a la meta de 0.0001 , pero produjo un error cuadrático medio mínimo de 0.00449451 .

Por otro lado, se obtuvieron y evaluaron modelos estadísticos de regresión de primer orden, primer orden con interacción y segundo orden, para las secuencias A y B. El promedio del error porcentual de las características fisicoquímicas entre las salidas obtenidas y las esperadas, estimadas por las RNAs y los modelos estadísticos de regresión, son presentados en la Tabla 2.

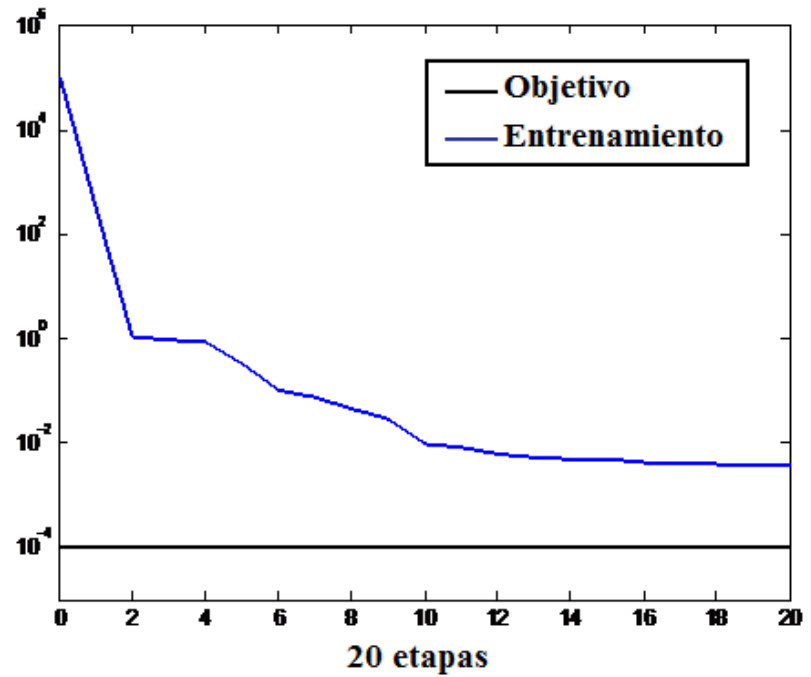

(a)

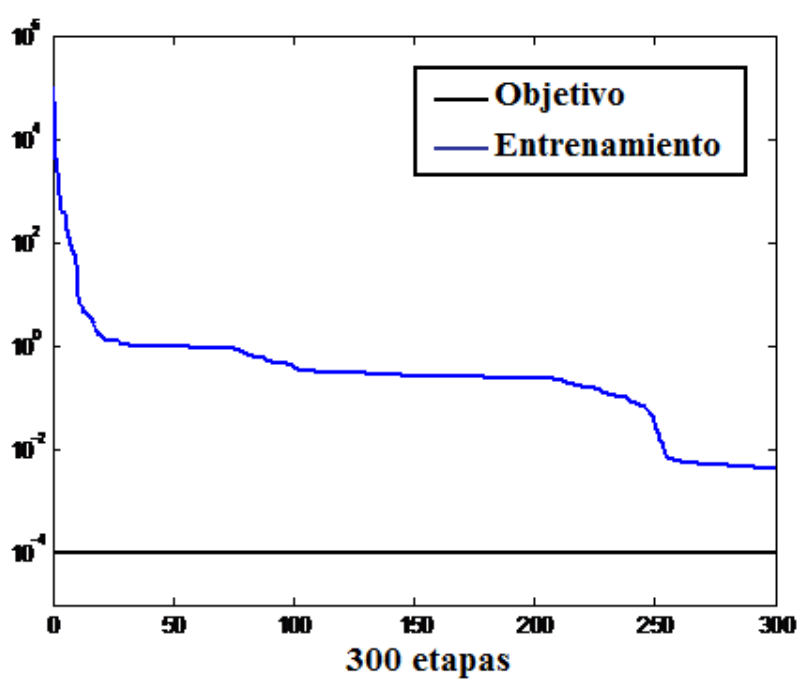

(b)

Figura 4. Desempeño del aprendizaje de los modelos neuronales: (a) Secuencia-A, (b) Secuencia-B 


\section{Tabla 2}

Promedio del error porcentual de las características fisicoquímicas de vinagre clarificado entre las salidas obtenidas y las esperadas, estimadas por RNA-A y RNA-B y modelos de regresión estadística

\begin{tabular}{|c|c|c|c|c|c|c|c|}
\hline \multirow[b]{2}{*}{ Características fisicoquímicas } & \multicolumn{3}{|c|}{$\begin{array}{c}\text { RNA-A y modelos de regresión } \\
\text { estadística }\end{array}$} & \multicolumn{4}{|c|}{$\begin{array}{c}\text { RNA-B y modelos de regresión } \\
\text { estadística }\end{array}$} \\
\hline & $\begin{array}{c}\text { RNA } \\
\text { A }\end{array}$ & $\begin{array}{c}\text { Modelo } \\
\text { de ler } \\
\text { orden }\end{array}$ & $\begin{array}{l}\text { Modelo de } \\
\text { 1er orden } \\
\text { con } \\
\text { interacción }\end{array}$ & $\begin{array}{c}\text { RNA } \\
\text { B }\end{array}$ & $\begin{array}{c}\text { Modelo } \\
\text { de ler } \\
\text { orden }\end{array}$ & $\begin{array}{l}\text { Modelo de } \\
\text { ler orden } \\
\text { con } \\
\text { interacción }\end{array}$ & $\begin{array}{c}\text { Modelo } \\
\text { de } \\
\text { segundo } \\
\text { orden }\end{array}$ \\
\hline $\mathrm{pH}$ & 0.03 & -0.21 & 18.53 & -0.12 & -0.13 & -0.26 & 0.64 \\
\hline Volumen (mL) & 0.09 & 0.00 & 0.00 & -0.37 & -0.15 & -0.13 & -0.15 \\
\hline Densidad $(\mathrm{g} / \mathrm{mL})$ & 0.02 & 0.43 & -28.16 & 0.57 & 0.02 & -0.44 & -2.19 \\
\hline Acidez total (g.ác.acético/100mL) & 0.75 & 0.54 & 3.49 & 0.05 & 0.51 & 0.67 & 0.38 \\
\hline Alcohol (\% vol) & 5.75 & 4.58 & 27.35 & 3.27 & 2.50 & 1.40 & 2.60 \\
\hline Aldehídos totales (mg acetaldeh/100mL) & 2.19 & 7.44 & 20.23 & 3.54 & 5.93 & 4.69 & 5.30 \\
\hline Furfural $(\mathrm{mg} / 100 \mathrm{~mL})$ & -3.68 & 0.08 & -8.72 & -2.28 & 1.47 & 1.51 & 2.34 \\
\hline Promedio & 0.74 & 1.84 & 4.67 & 0.67 & 1.45 & 1.06 & 1.27 \\
\hline
\end{tabular}

La RNA-A arrojó una matriz singular con determinante cero para un modelo de segundo orden, por lo que no se consideró para el análisis. Se observa que la RNA-A es más adecuada que un modelo de regresión de primer orden sin interacción, en la predicción de las características fisicoquímicas del vinagre. Asimismo, la RNA-B resulta ser más adecuada que un modelo de regresión de primer orden con interacción, para la predicción de los parámetros físicoquímicos del vinagre.

En el entrenamiento de la red se pueden usar patrones de entrada y salida normalizados o escalados mediante una transformación en los intervalos $[0,1]$ ó $[-1,1]$. La transformación de los patrones no es una condición necesaria para realizar el aprendizaje de la red, también los datos pueden presentarse a la red, sin dicha normalización (Isasi y Galván, 2004). En esta investigación no se utilizaron patrones normalizados o escalados. El algoritmo de ajuste de pesos de "Levenberg-Marquardt" (LM) es un método más sofisticado que el gradiente descendente, que proporciona, entre otras mejoras, menor tiempo de entrenamiento. Jaramillo et al. (2006) reportan su uso en una Red Neuronal "feedforward" con neuronas tipo sigmoide para en la identificación y simulación de un reactor aerobio de lodos activos. Según Lamrini et al. (2005), este algoritmo penaliza los pesos débiles, proporcionando una medida fiable de cuántos pesos se usa eficientemente en la Red Neuronal.

La Red de retropropagación de una única capa oculta puede aproximar hasta un nivel deseado cualquier función continua, en este sentido el algoritmo BP ha sido dado a conocer por su gran potencial para la resolución de problemas prácticos, siendo una de sus aplicaciones más importantes el de la predicción (Martin de Brío y Sanz Molina, 2002).

En la presente investigación se usó igualmente una Red feedforward (FF), para las dos secuencias (A y B) y análogamente los algoritmos de entrenamiento BP y de ajuste de pesos LM con buena efectividad para los efectos predictivos, considerándose de manera similar un mínimo de error o error meta de $1 \times 10^{-4}$. Se consideró este error debido a rangos de desviación del promedio de los valores experimentales más bajos fueron para el furfural de $1 \times 10^{-2}$ y para la densidad de $1.67 \times 10^{-4}$.

El número de capas ocultas y neuronas son elegidas por el diseñador (Isasi y Galván, 2004) las que son determinadas por prueba y error, no existiendo método o regla que determine su número óptimo. Lamrini et al. (2005) mencionan que sólo una capa oculta es 
suficiente para modelar cualquier sistema continuo, si esta capa contiene suficientes neuronas. Isasi y Galván (2004) sostienen que el cambio en el peso de una RNA es proporcional a la gradiente del error, la cual viene dada por la razón o tasa de aprendizaje $(\alpha)$, quien controla el desplazamiento de los pesos de la red en la superficie del error siguiendo la dirección negativa del gradiente, influyendo en la velocidad de convergencia del algoritmo. Valores altos de $\alpha$, pueden favorecer una convergencia rápida, pero pueden sobrepasar el mínimo (Isasi y Galván, 2004). Valores pequeños podrían evitar estos problemas, aunque a costa de una convergencia más lenta del aprendizaje (Demuth y Beale, 2005). Isasi y Galván (2004) manifiestan que una tasa de aprendizaje para un determinado problema podría ser pequeña o demasiado grande para otro problema. Un método para evitar la inestabilidad en el algoritmo de aprendizaje debido a $\alpha$, es mediante la inclusión del término "momento". Según refieren Isasi y Galván (2004), la utilización del "momento" procura un cambio mayor en el peso, acelerando la convergencia del algoritmo.

En esta investigación, los criterios de Isasi y Galván (2004), no tuvieron los resultados esperados, ya que se practicó una variación de $\alpha$ de $1 \times 10^{-11}$ a 1 , no influenciando en el valor del mse, el cual se mantuvo constante. Asimismo la variación del coeficiente de "momento" de 0 a 1, tampoco influenció en el mse, manteniéndose igualmente constante.

Se obtuvo para la RNA-A, para el pH, volumen, densidad, acidez total, contenidos de alcohol, acetaldehído y furfural, un promedio del error porcentual (\%), entre las salidas obtenidas y las salidas esperadas, entre -3.68 $\mathrm{y}+5.75 \%$. En la RNA-B errores entre -2.28 y +3.54\%. Lamrini et al. (2005) propusieron modelos neuronales para la predicción, con mse entre 0.005 y 0.011 , los cuales tuvieron excelente calidad de predicción entre las salidas de la red y los datos reales. En adición, Martin del Brío y Sanz-Molina (2002), obtuvieron y evaluaron modelos de regresión estadístico, habiendo observado similitud predictiva de las Redes Neuronales con respecto a los modelos estadísticos $(\mathrm{p}>0.05)$ de primer orden y primer orden con interacción, a través del análisis de variancia (ANVA). En nuestros resultados, a excepción de la densidad para la RNA-A, donde se observó que existe diferencia significativa $(\mathrm{p}<0.05)$ de los valores con respecto al modelo de regresión estadística de primer orden; y aunada a la inconsistencia para predecir el contenido de furfural $\left(\mathrm{R}^{2}=0.37617 \mathrm{y}\right.$ $\mathrm{p}=0.11197>0.05$.) indica la imperfección del modelo con respecto al de la Red Neuronal. En cambio en la RNA-B, se observa que no existe diferencia significativa $(\mathrm{p}>0.05)$ de las características fisicoquímicas obtenidas por los modelos neuronal y estadístico, con respecto a los valores experimentales; lo que indica la solidez predictiva de ambos modelos.

\section{Conclusiones}

La mejor predicción para la secuencia A (entradas: promedio de temperatura de alimentación al evaporador flash, promedio de presión de vacío en el evaporador flash, tiempo de alimentación al evaporador flash, temperatura de destilación, $\mathrm{pH}$ y volumen de vinagre oscuro de entrada al destilador flash), se logró utilizando la Red Neuronal feedforward (RNA-A), con algoritmos de entrenamiento BP y de ajuste de pesos LM; con la topología tansig-purelin, 6 entradas, 7 salidas lineales, 9 neuronas en 1 capa oculta, coeficiente de momento 0.5, tasa de aprendizaje 0.01 , meta del error 0.0001 y 20 etapas de entrenamiento. Se observó a través de un ANVA y análisis por Diferencia Mínima Significativa (DMS), similitud predictiva de la RNA-A con respecto al modelo estadístico de primer orden y los valores deseados $(\mathrm{p}>0.05)$ de $\mathrm{pH}$, acidez total, contenidos de alcohol, aldehídos totales y furfural. A excepción de la densidad, en la cual se ha observado diferencia significativa $(p<0.05)$ de los valores, con respecto al 
modelo de regresión estadística de primer orden, aunada a la inconsistencia del modelo estadístico para predecir el contenido de furfural $\left(\mathrm{R}^{2}=0.37617\right.$ y $\mathrm{p}=0.11197>0.05$. $)$ lo que indicó la imperfección del modelo con respecto al de la Red Neuronal.

La mejor predicción para la secuencia B (entradas: promedio de temperatura y tiempo de alimentación al evaporador flash), se logró utilizando la Red Neuronal feedforward (RNA-B), con algoritmos de entrenamiento BP y de ajuste de pesos LM, con la topología logsig-purelin, 2 entradas, 7 salidas lineales, 84 neuronas en 1 capa oculta, coeficiente de momento 0.5 , tasa de aprendizaje 0.01, meta del error 0.0001 y 300 etapas de entrenamiento. Se observó similitud predictiva de la RNA-B, con respecto al modelo estadístico de primer orden con interacción de términos y con los valores deseados $(\mathrm{p}>0.05)$ de $\mathrm{pH}$, densidad, acidez total, contenidos de alcohol, aldehídos totales y furfural; indicando la solidez predictiva de ambos modelos.

\section{Referencias}

Achaerandio, I.; Güell, C.; López, F. 2002a. Continuos Vinegar Decoloration with Exchange Resins. Journal of Food Engineering 51 (4): 311-317.

Achaerandio, I; Güell, C; Medina, F.; Lamuela-Raventos, R.; López, F. 2002b. Vinegar Decolourization by ReActivated Carbon. Food Science \& Technology International 8 (4): 239-242.

Al-Shayji, K. A.; Al-wadei, S.; Elkamel, A. 2005. Modeling and Optimization of multistage flash desalination process. Engineering optimization 37 (6): 591-607.

Brabec, M. J. 1981. Aldehydes and Acetals. Edit. Patty's Industrial Hygiene and Toxicology. Vol. II A, Toxicology. New York. John Wiley \& Sons, Inc.

Cruz, A. J. G.; Silva, A. S.; Araujo, M. L. G. C.; Giordano, R. C.; Hokka, O. 1999. Estimation of the Volumetric Oxygen Transfer Coefficient (KLa) from the Gas Balance and Using a Neural Network Technique. Braz. J. Chem. Eng. 16 (2): 179-183.

Demuth, H.; Beale, M. 2005. Neural Network Tollbox for Use with MATLAB. User's Guide. Version 4. The Maths Works, Inc.

FAO, 2001. Informe de la $33^{\text {a }}$ Reunión del Comité del Codex Sobre Aditivos alimentarios y Contaminantes de los Alimentos. Disponible en: http://www.fao.org/docrep/meeting/005/y0474s/y0474s7i. htm

Fasset, D. 1983. Aldehydes and Esters. Edit. New York. 1959 $-1960$.
García, M.; López-Mungia, A. 1993. Bebidas Alcohólicas no Destiladas. Biotecnología Alimentaria. Edit. Limusa Noriega Editores. México. Pp. 263 - 311.

Gerbi, V.; Zeppa, G.; Beltramo, R.; Carnacini, A.; Antonelli, A. 1998. Characterization of White Vinegars of Different Sources with Artificial Neural Networks. J Sci.Food Agric. Great Britain 78: 417-422.

Hussain, M. A.; Rhaman, M. S.; Ng, C. W. 2002. Prediction of Pores Formation (Porosity) in Foods During Drying: Generic Models by the Use of Hybrid Neural Network. Journal of Food Engineering 51: 239-248.

Ince, E.; Kirbaslar, S. 2002. Liquid-Liquid Equilibria of the Water-Acetic Acid-Butyl Acetate System. Braz. J. Chem. Eng. 19 (2): 243-254.

Isasi, P.: Galván, I. 2004. Redes Neuronales Artificiales. Un Enfoque Práctico. Edit. Pearson Prentice Hall. Madrid. España.

INDECOPI - Instituto Nacional de Defensa de la Competencia y de la Protección Intelectual. 1970. NTP 209.020. Vinagre. Lima - Perú.

INDECOPI - Instituto Nacional de Defensa de la Competencia y de la Protección Intelectual. 2003-a. NTP 210.020. Bebidas Alcohólicas. Determinación de Aldehídos Totales. Lima - Perú.

INDECOPI - Instituto Nacional de Defensa de la Competencia y de la Protección Intelectual. 2003-b. NTP 210.025. Bebidas Alcohólicas. Determinación de Furfural. Lima - Perú.

INDECOPI - Instituto Nacional de Defensa de la Competencia y de la Protección Intelectual. 2002. NTP 211.001. Bebidas Alcohólicas. Pisco requisitos. Lima Perú.

Jaramillo, M.; Peguero, J.; de Salazar Martínez, E.; García del Valle, M. 2006. Identificación y Simulación de un Reactor Aerobio Mediante Redes Neuronales. Centro Universitario de Mérida. Universidad de Extremadura España. Disponible en: http://www.ceaifac.es/actividades/jornadas/XXI/documentos/ja00_050/ja 00_050.pdf

Joint FAO/WHO Food Standars Programe, 1987. Codex Standards for Sugars, Cocoa Products and Chocolate and Miscellaneous. Codex Standad for Vinegar. In Codex Alimentarius. Regional European standard, Codex Stan 162. Ginebra.

Lamrini, B.; Benhammou, A.; Le Lann, N.; Karama, A. 2005. Neural Software Sensor for Online Prediction of Coagulant Dosage in a Drinking Water Treatment Plant. Transactions of the Institute of Measurement and Control 27 (3): 195-213.

López, F.; Medina, F.; Prodanov, M.; Güell, C. 2003. Oxidation of Activated Carbon: Application to Vinegar Decolorization. Journal of Colloid \& Interface Science 257 (2): 173.

Liu, F.; Wang, L.; Yong, H. 2008. Measurement of Sugar Content of White Vinegars Using Vis/Near-Infrared Spectroscopy and Backpropagation Neural Networks. Proceding of the Seventh International Conference on Machine Learning and Cybernetics. Kunming. China 1311-1316.

Martín del Brio, B.; Sanz Molina, A. 2002. Redes Neuronales y Sistemas Difusos. Edit. Alfa Omega Ra-Ma. Madrid. España. 
Matissek, R.; Schnepel, F. M.; Steiner, G. 1998. Análisis de los Alimentos. Fundamentos - Métodos- Aplicaciones. Edit. Ecribia, S.A. Zaragoza. España.

Mendes, E. F. F. 1999. Redes Neurais: Introdução a Redes Neurais Artificiais, Algorítmos Genéticos e Aplicações. Disponível en: http://www.icmc.sc.usp.br/ prico/ neurall.html

MINAG - Ministerio de Agricultura. 2009. Caracterización del Departamento de la Libertad. Disponible en: htt://www.bcrp.gob.pe/docs/sucursales/Trujillo/la libertad-caracterización.pdf

Nalbant, M.; Gokkaya, H.; Tortas, I. 2007. Comparison of Regression and Artificial Neural Network Models for Surface Roughness Prediction with the Cutting Parameters in CNC Turning. Hindawi Publishing Corporation. Modelling and Simulation in Engineering. Disponible en: http://www.hindawi.com/journals/mse/ 2007/092717.abs.html

Ott, D. 1987. Manual de Laboratorio de Ciencias de Alimentos. Edit. Acribia S.A. Zaragoza. España.

Ovejero, M. A.; Lesino, G. 2003. Ensayo de un Conjunto Evaporador Eyector. Avances en Energías Renovables y Medio Ambiente. ASADES. 7 (2). Argentina.

Olmedo, E.; Valderas, J. M.; Mateos, R.; Gimeno, R. 2006. Utilización de Redes Neuronales en la Caracterización, Modelación y Predicción de Series Temporales Económicas en un Entorno Complejo. Universidad de San Pablo - Universidad Pontificia Comillas. España. 1-19.

Ovejero, M. A.; Salvo, N.; Lesino, G. 2000. Resultados preliminares del comportamiento de un evaporador por flash a escala de laboratorio para generación de electricidad a baja temperatura. ASADES 4 (1): 343-348. Resistencia, Argentina.
Pietrzyk, D.; Frank, C. 1983. Química Analítica. Nueva Editorial Interamericana S.A. México D.

Pérez-Akasuso, I; Ibarz-Rivas, A.; Pomar-Gomá, J. 2004. Calculo de Evaporadores. Escuela Superior de Ingeniería Agraria, Universidad de Lleida. España. Edit. Fito, P.; Mulet, A.; Ordica, C.; Bon, J. Disponible en: http://www.upv.es/dtalim/herraweb.htm

Reglamento Sanitario de Manejo de Residuos Peligrosos. 2006. Diario Oficial $\mathrm{N}^{\mathrm{o}}$ 209. Republica de Chile Ministerio de Salud.

Scenna, N. J. 1999. Modulo de Simulación de Evaporadores Flash. Modelado, Simulación y Optimización de Procesos Químicos. Edit. Scenna, N.J. 345 - 372.

Suaréz, J. 2002. Impacto de Levaduras y Bacterias en los Aromas Vínicos Fermentativos. Análisis Sensorial-Vino. Ponencias CSCS 2002. Universidad Politécnica de Madrid. 1-4.

Spinnler, M.; Blumenberg, J.; Moik, W.; Müller-Holst, H.; Krispler, H.U. 2000. Small-Scale Systems for SolarThermal Desalination of Sea and Brackish Water; India Narosa Publishing House, Renewable Energy Technologies, Vol. Applications to Industries and Agriculture, pages 179-189.

Tesfaye, W.; Morales, M. L.; García-Parrilla, M. C.; Troncoso, A.M. 2002. Wine Vinegar: Technology, Authenticity and Quality Evaluation. Trends in Food Science \& Technology 13(1): 12-21.

The vinegar Institute 2003. Disponible en: http://www.versatilevinegar.org 